\title{
A Long Term or a Major Migration
}

\author{
Chunke $\mathrm{Hu}^{1, \mathrm{a}}$ \\ ${ }^{1}$ School of North China Electric Power University, Hebei 071000, China; \\ a526570308@qq.com
}

Keywords: migration, urban development, population distribution, social capacity

\begin{abstract}
When we study a 100-year-vision migration (a long term plan), the population distribution is required to be considered. The young or aging problem and a large proportion of the non-working population are introduced and when the quantized influence of three factors (income, education and social equality) is appropriate, urban development will be in the local optimal situation.

In addition, considering the newly moved do not have fixed residence or employment in a major migration, a larger proportion of the social resources will be provided to them, therefore, we introduce social capacity. When the migration population is beyond the social capacity, with a larger migration population, the transition stage will be longer and the impact to social development will be greater.
\end{abstract}

\section{Introduction}

The international agency, Laboratory of Interstellar Financial \& Exploration Policy (LIFE), has recently (in this year of 2095) completed a series of short-term planned living experiments on our neighbor planet, Mars. New technologies will soon enable humans to inhabit manufactured cities on Mars by 2100. The first wave of migration, called Population Zero, will include 10,000 people.

In order to create a sustainable life-plan and make the living experience on Mars even better than the Earthly one, we need to consider about an additional migration phased over the next 100 years as well as a major migration.

\section{Additional Migration Phased Over the Next 100 Years}

\section{Influence of Population Distribution.}

The plan for the additional migration phased over the next 100 years (a long term plan) is obviously different from a 10-year plan, the short term plan, in the following two aspects. ${ }^{[1]}$

First, the long-term migration cannot guarantee that the ideal requirement for Population Zero is satisfied by each group of people migrated to Mars. When the goal of creating an optimal workforce to give all people the greatest quality of life with a vision of sustainability is satisfied perfectly, more kinds of people will be willing to migrate to Mars, therefore, the kinds of people recruited to migrate to Mars will be various, leading to a much more complex population composition.

Second, some social contradictions will be prominent considering the long-term migration. The early migrants will be faced with problems like child birth and aging population, which will result in impact to the society in Mars and some adjustments are required for the evaluation indicators.

What's more, we will discuss how to improve and adjust the indicator of sustainable urban development when problem like the young or aging population is severe or non-working population (like the disabled) occupy a certain or even a large proportion, besides, the revised indicator needs to satisfy the effect of Population Zero as well.

\section{The Young or Aging Population.}

The unemployment rate will decline in a phase where problem of the young or aging population is severe, while the phenomenon can be interpreted from the perspective below. Take the aging population for an example. Demand for consumption and service of the old will increase along with the aging process. Besides, change of the consumption structure will bring a further transformation to the production structure. Constructing public pension facilities and activities for the old and 
increasing corresponding service projects for the old will bring plenty of jobs. The influence above will all help to reduce the unemployment rate.

Secondly, when the old or the young occupy a large proportion in the population, the government will increase the welfare investment to pension or education in a way to reduce burden to the family from the old or the young. As a result, indicator of sustainable urban development will be affected, for the influence to the society in terms of income will reduce and influence to the society in terms of social equality will increase, but the overall effect will reduce, resulting in job oversupply.

\section{A Large Proportion of the Non-working Population.}

The unemployment rate and social welfare will also be influenced in a phase where non-working population (like the disabled) occupy a certain or even a large proportion.

On the one hand, since the disabled are always incapable and dependent, specific service or medical projects will be set for them in the society, which will bring jobs and reduce unemployment rate in a way. However, the increase of the disabled is limited and the existing service or medical projects are capable to provide required service for the disabled in reality, therefore, influence to the unemployment rate because of the increase of the disabled can be negligible.

On the other hand, with the lack of work ability, the disabled will lead heavy load to the family. Therefore, the welfare policy needs to be improved along with increase of the disabled. The government is required to raise the proportion of social welfare in the gross domestic product (GDP) to maintain the sustainable urban development, which will influence the indicator of sustainable urban development directly.

\section{Local Optimal Indicator of Sustainable Urban Development.}

The indicator of sustainable urban development has a local optimal solution relative to the three factors (income, education and social equality), when the three factors occupy a appropriate proportion, that is, when the influence of the three factors to the society get appropriate magnitudes, indicator of sustainable urban development will get the local optimal solution. Since the three factors are concerned with unemployment rate, social and the total population, we get the change trend chart through Matlab based on the data collected before and the trend chart is shown in Figure 1.

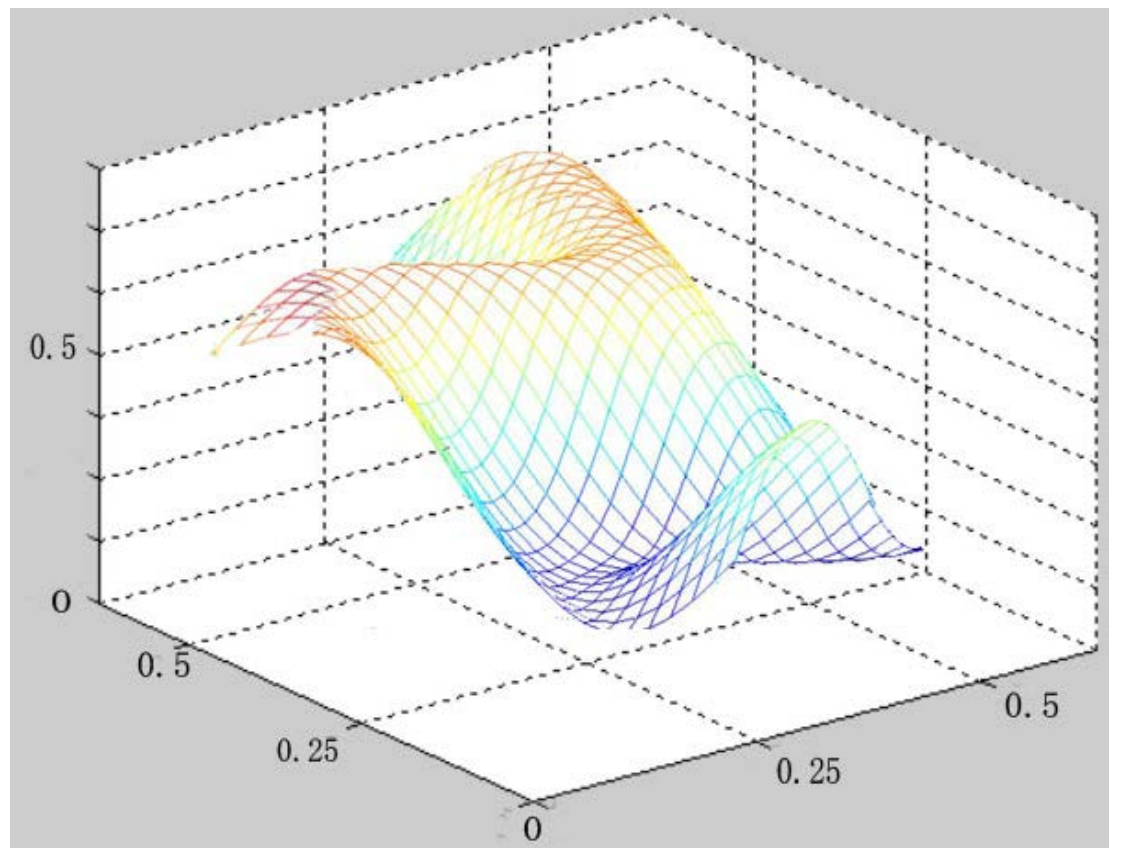

Fig. 1 Trend chart of the indicator of sustainable urban development $t$

As a result, when the society is in a steady development, the urban development will tend to be sustainable. While the population factor in a sustainable urban development depends not only on the number, but also relative to the distribution of people. 


\section{A Major Migration}

When a major migration takes place, we need to move as many people as possible. Since the newly moved do not have fixed residence or employment, a larger proportion of the social resources will be provided to them, therefore, we are required to consider social capacity and introduce the migrant state and transition stage compared with the normal stage.

Considering the incompleteness of data and the unpredictability of a major migration, we just offer a method rather than concrete computation.

Among the metrics we set before, the original data we choose include unemployment rate, ratio of social welfare in gross domestic product (GDP), ratio of education in welfare investment, gross domestic product (GDP), minimum wage standard, the proportion of the number of people and gross domestic product in the three major industries, gender proportion and total population. While we neglect the influence of natural resources, the ratio of social welfare in gross domestic product (GDP), ratio of education in welfare investment, gross domestic product (GDP) and total population can be considered as resources to the individual from the society. When the society is developing steadily, social resources will be divided to the required and this is a normal state. ${ }^{[2]}$

When a major migration takes place, considering the newly moved do not have fixed residence or employment, a larger proportion of the social resources will be provided to them, and the remaining social resources will be divided to the original residents on Mars, and the concrete data will be determined by the concrete population constitution, while this is a migrant state.

In different social development stage, the largest population within capacity of the current society differs. Therefore, according to the migrant population, length of the corresponding transition stage varies as shown in Figure 2, which can be obtained from statistics.

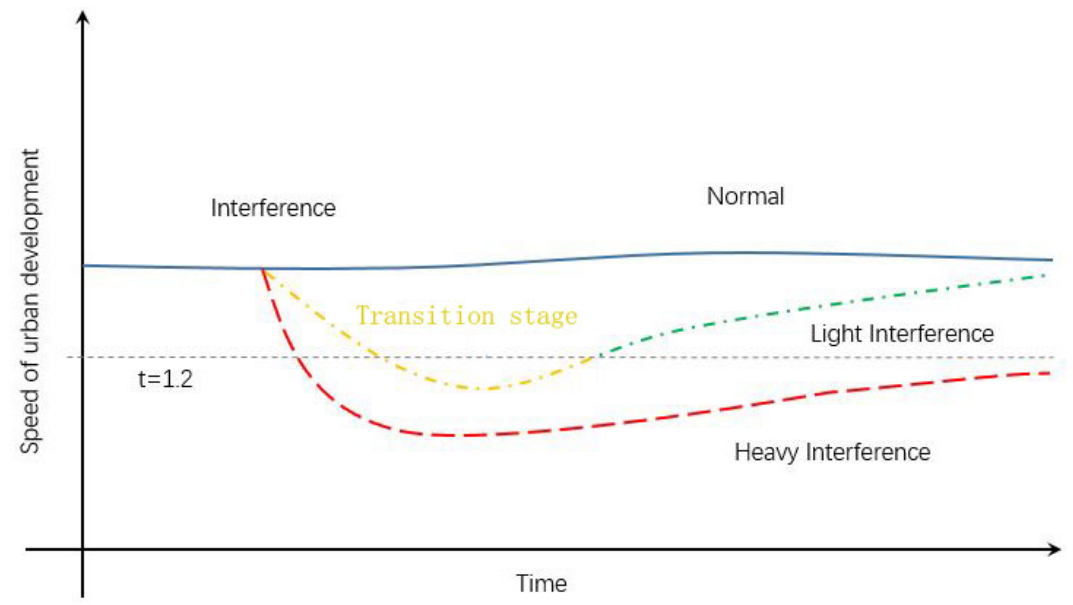

Fig. 2 Transition stage relative to the migrant population

As a result, when a major migration takes place, if the social resources in the migrant state are capable to keep all the residents through the transition stage, the model we constructed could still hold. However, if the social resources in the migrant state are incapable to keep all the residents through the transition stage, the model we constructed could not work anymore, and we need to rebuild a effective model to solve the new problem.

When migrations occur in phases, on the one hand, the computation can be accomplished through the method above. On the other hand, we can go back to the previous part concerning the additional migration phased over the next 100 years and apply the previous method according to the population constitution.

\section{Conclusions}

In the migration phased over the next 100-years, composition of the population will change drastically along with the young or aging problem and a large proportion of the non-working population, which can be solved by adjustment to the relevant parameters to guarantee the effectiveness of the model. 
If large quantities of migrants are assigned in a short period of time, social capacity on Mars will be taken into account. When migration exceeds the capacity, a larger migration population will result in a longer transition stage and greater impact to social development.

\section{References}

[1] Zachariah K C, Rajan S I. Migration, Remittances and Short-term Trends and Long-term Implications[J]. Centre for Development Studies Trivendrum Working Papers, 2016.

[2] Ning G J. Chinese Minimum Wage Standard Formulation and Adjustment According to the Empirical Analysis[J]. Chinese Population Science, 2011, 2011 (1): 26-34. 